\title{
Combined drought and bark beetle attacks deplete non-structural carbohydrates and promote death of mature pine trees
}

\author{
Nadir Erbilgin ${ }^{1}$, Leila Zanganeh ${ }^{1}$, Jennifer Klutsch ${ }^{2}$, Shih-hsuan Chen ${ }^{1}$, Shiyang ZHAO ${ }^{1}$, \\ Guncha Ishangulyyeva $^{1}$, Stephen Burr ${ }^{3}$, Monica Gaylord ${ }^{4}$, Richard Hofstetter ${ }^{5}$, Ken \\ Keefover-Ring ${ }^{6}$, Kenneth F. Raffa ${ }^{6}$, and Thomas Kolb ${ }^{2}$ \\ ${ }^{1}$ University of Alberta \\ ${ }^{2}$ Affiliation not available \\ ${ }^{3}$ USDA Forest Service Alaska Region \\ ${ }^{4}$ USDA Forest Service Flagstaff Forestry Sciences Laboratory \\ ${ }^{5}$ Northern Arizona University \\ ${ }^{6}$ University of Wisconsin Madison
}

July 6, 2021

\begin{abstract}
How carbohydrate reserves change in conifers during drought and bark beetle attacks are poorly understood. We investigated changes in carbohydrate reserves and carbon-dependent terpene defenses in ponderosa pine trees experimentally subjected to two levels of drought stress (via root trenching) and two types of biotic challenge treatments (pheromone-induced bark beetle attacks or inoculations with crushed beetles that include beetle-associated fungi) for two consecutive years. Our results showed that trenching did not influence carbohydrates whereas both biotic challenges reduced amounts of starch and sugars of trees. However, only the trenched-beetle attacked trees depleted carbohydrates and died within the first year of bark beetle attacks. While live trees contained higher carbohydrates than dying trees, amounts of constitutive and induced terpenes produced did not vary between live and beetle-attacked dying trees, respectively. Based on these results we propose that reallocation of carbohydrates to terpenes during the early stages of beetle attacks is limited in drought-stricken trees, and that the combination of biotic and abiotic stress leads to tree death. The process tree death is subsequently aggravated by beetle girdling of phloem, occlusion of vascular tissue by bark beetle-vectored fungi, and potential exploitation of host carbohydrates by beetle symbionts as nutrients.
\end{abstract}

\section{Introduction}

Climate change-induced dieback is a global problem affecting forest ecosystems worldwide (Allen et al. 2010; Anderegg et al.2012; Young et al. 2017; Hartmann et al. 2018). The causal factors underlying forest dieback have been commonly attributed to complex interactions between abiotic and biotic factors (SimlerWilliamson et al. 2019). For instance, drought is often viewed as a predisposing factor responsible for promoting outbreaks by some insect species such as bark beetles (Coleoptera: Curculionidae, Scolytinae) that attack the main stems of mature trees (Gaylord et al. 2013; Anderegg et al. 2015; Netherer et al. 2019; Gely et al. 2020; Öhrn et al . 2021). Although there are proposed mechanisms underlying drought-induced tree mortality, i.e., a failure of the plant's water transport-hydraulic-system and carbon starvation due to prolonged stomatal closure and reduced photosynthesis (McDowell et al. 2008; Anderegg et al. 2012; Meir et al. 2015; Adams et al. 2017; Choat et al. 2018; Hartmannet al. 2018), we have less understanding of the combined effects of drought and insect attacks in the field (Kolb et al. 2016; Stephenson et al. 2019; Huang et al. 2020). Significant challenges in conducting field experiments include experimental control of both water 
stress and bark beetle attacks on the mature trees, and measurement of the cascading physiological changes through tree death (Kolb et al. 2016; Choat et al. 2018).

Most studies focusing on tree mortality were either conducted during or after observed mortality (retrospectively) (e.g., Camarero et al.2015; Gaylord et al. 2013; 2015; Kolb et al. 2016; Öhrnet al . 2021). Moreover, those studies primarily examined the role of a single stress agent such as drought or herbivory (e.g., Meddenset al. 2014; Erbilgin et al. 2017) although their effects can be interacting. Likewise, some studies utilized seedlings under controlled conditions to improve standardization (i.e., Turtola et al. 2003; Lusebrink et al. 2011) but it is well recognized that plant ontogeny strongly affects many responses and thus results obtained with seedlings may not be applicable to mature trees (Boege \& Marquis, 2005; Erbilgin \& Colgan, 2012; Moreira et al. 2017). As such, experimental demonstrations of both predisposing and biotic factors leading to?and measuring the physiological mechanisms responsible for?tree mortality in the field are sparse (Kolb et al. 2016; Huang et al. 2020). This knowledge gap hinders our ability to accurately understand the mechanism of tree mortality from multiple and sometimes synergistic factors.

Drought can have profound impacts on tree responses to subsequent insect attacks. These responses vary by feeding guild and are most impactful with bark and wood boring insects (reviewed by Kolb et al. 2016). Briefly, prolonged droughts induce stomatal closure, which in turn reduces photosynthesis, potentially leading to depletion of carbohydrate reserves, i.e., non-structural carbohydrates (NSCs), comprised of soluble sugars and starch (McDowell et al. 2008; Anderegget al. 2012; Mitchell et al. 2013; Choat et al.2018). Hydraulic failure occurs due to disruption of water movement in the xylem due to formation of air bubbles (embolism) during desiccation (Adams et al. 2017). Furthermore, NSC depletion may also reduce water movement and retention, promoting cellular dehydration (Salaet al. 2012; Deans et al. 2020). Reductions in carbohydrate production and depletion of NSCs due to drought can influence many functions in plants including biosynthesis of carbon-dependent terpenes that serve antidessication and antiherbivory functions (McDowell et al. 2011; Huang et al. 2020; Hussain et al. 2020).

Ponderosa pine (Pinus ponderosa) is one of the most widely distributed conifer species in western North America, ranging from southern Canada to Mexico, and from the Plains States to the Pacific Coast. Two major threats to ponderosa pines, and other co-occurring pine species, are drought and bark beetles (Negron et al. 2009; Bentzet al. 2010; Raffa et al. 2013; Creeden et al.2014). Over recent decades, several million ponderosa pine trees were killed by a combination of these two stressors in various parts of the species' range (Savage et al. 1994; USDA Forest Service 2002; Breshears et al. 2005; Allen et al. 2010; Pile et al. 2019).

Bark beetles' reproduction involves offspring completing their development within the phloem layer beneath the outer bark of their host trees. Pine phloem contains toxic carbon-dependent secondary metabolites including monoterpenes, diterpene resin acids, and phenolics (Francheshiet al. 2005; Keeling \& Bohlmann 2006; Celedon \& Bohlmann 2019; Erbilgin, 2019). Studies have reported that monoterpenes and diterpenes are toxic to the bark beetles and their mutualistic fungi (Kopperet al. 2005; Chiu et al. 2017; Ullah et al. 2021). Numerous studies with simulated or actual herbivore attacks have extensively shown mobilization and transport of stored NSCs in support of the synthesis of defense metabolites in plants including conifers (Goodsman et al . 2013; Dietze et al. 2014; Hartmann \& Trumbore 2016; Adams et al . 2017; Li et al . 2018; Rothet al . 2018; Hussain et al . 2020). Effects of drought on bark beetles can be positive or negative depending on drought intensity and duration (Lombardero et al. 2000; Gaylord et al. 2013, 2015). Currently, we lack a clear understanding about the importance of combined drought and bark beetle attacks on NSCs, carbon-based defense metabolites, and their interactions in tree mortality (Kolb et al. 2016; Huang et al. 2020).

An earlier study suggested a relationship between drought and ponderosa pine terpene defenses (Kolb et al. 2019), but how drought and biotic challenges interact to influence NSCs and their relationships with carbondependent defense metabolites (terpenes) has not been jointly investigated and remains poorly understood. Thus, our primary objective was to characterize the changes in NSC and terpene concentrations in ponderosa pine trees that were experimentally exposed to a factorial combination of drought stress (induced via root trenching), pheromone-induced bark beetle attacks, and crushing beetles onto phloem/xylem interface in the 
experiment described in Kolb et al . (2019). We hypothesized that the combination of drought and bark beetle attacks more rapidly deplete NSCs in tree stems that either stress agent alone, thereby eliciting tree mortality. We addressed the following five research questions: (1) Do drought stress, bark beetle attacks, and the beetle crushing influence NSCs of ponderosa pine trees? (2) Does drought impact the effect of biotic stressors on NSCs and terpenes? (3) Do changes in NSCs result in changes in defense metabolites? (4) Do concentrations of NSCs and defense metabolites vary between live and dying ponderosa pine trees? (5) Can interactions between NSCs and defense metabolites in dying ponderosa pine trees explain their mortality?

\section{Materials and Methods}

\section{Experimental approach}

The study was conducted in a naturally regenerated ponderosa pine-dominated stand at the Northern Arizona University's Centennial Forest (35deg 11' 9.65” N, 111deg 45' 38.25” W; elevation 2,250 m). We administered two levels of drought stress and two types of biological challenge treatments. Drought stress was administered by cutting tree roots beneath the drip line (hereafter trenched or untrenched). The biological treatments were (1) bark beetle attacks (hereafter attacked), (2) crushing beetles, including their microbial associates, onto the phloem/xylem interface (hereafter inoculated), and (3) controls which had neither bark beetle attacks nor inoculations.

The experiment was a randomized complete block with eight spatial blocks within the stand. In each of the eight $1,300 \mathrm{~m}^{2}$ blocks, six trees were randomly assigned to one of the following six treatments $(\mathrm{n}=8$ per treatment across eight blocks): (1) trenched-control, (2) trenched-inoculated, (3) trenched-attacked, (4) untrenched-control, (5) untrenched-inoculated, and (6) untrenched-attacked. The trees were approximately 60 years of old, with a mean height of 8.0+-0.12 m (range 5.2-11.5 m) and a mean diameter at breast height of 24.2+-0.5 cm (range 20.0-31.9 cm). Neither height nor diameter of trees varied among treatments (height: $\mathrm{P}=0.464$; diameter: $\mathrm{P}=0.133$ ).

Detailed descriptions of field experimental methods were provided in Kolb et al. (2019) which reported results for resin flow, monoterpenes and sesquiterpenes in the phloem, xylem water potential, and leaf gas exchange. In the current study, we focused on monthly analyses of NSCs and diterpenes of xylem and thus only reported methods relevant to these analyses. We also used the total monoterpene data from Kolb et al . (2019) in our analysis.

\section{Drought treatments}

We cut trenches beneath the drip line of 24 trees ( $\mathrm{n}=3$ per block) on May 20-21, 2013 using methods modified from Devine \& Harrington (2008). Trenches were cut to $33 \mathrm{~cm}$ deep using a ditch witch and the interior walls were lined with $0.15 \mathrm{~mm}$ thick polyethylene sheeting to restrict root growth and water access. Each trench was then backfilled with soil. We also removed snow within the same drip lines of trenched trees after every major snowfall during the winter of 2013. As described in Kolbet al . (2019), the study measured tree predawn water potential and the trenching treatment produced a level of water stress consistent with moderate drought, similar to previous uses of this method with ponderosa pine (McCullough \& Wagner, 1987). We briefly summarized the results from Kolb et al . (2019) under Result section below.

\section{Biological challenge treatments}

We administered two biological challenge treatments and one control treatment. The first treatment involved attaching bark beetle pheromones (Dendroctonus brevicomis lures; Synergy Semiochemicals Corp. Burnaby, BC CAN) on selected trees at $1.5 \mathrm{~m}$ height on June 2, 2014 (app. one year after trenching). We baited 16 trees, with one tree in each of the trenched and untrenched treatments across eight blocks. We monitored baited trees twice weekly and considered trees with pitch tubes (small bark beetle boring holes filled with boring dust, frass, and resin) as attacked. We counted all beetle attacks on each tree up to $3.5 \mathrm{~m}$ height. Once the number of attacks on a tree reached 150, we removed baits from that tree. Overall, the mean number of attacks per baited tree was $90+-9 \mathrm{~m}^{2}$ and did not vary between trenched and untrenched trees $(\mathrm{P}=0.161)$. 
The second treatment consisted of crushing beetles, in a 3:1 ratio of $D$. brevicomis to $D$. frontalis, onto the phloem/xylem interface to inoculate trees with the full complement of microbial biota, primarily fungi but also including bacteria, mites, and nematodes (Hofstetter et al. 2015), associated with D. brevicomis ,D. frontalis, and $D$. valens, the most dominant bark beetle species affecting pine forests of the study region (Gaylord et al. 2006). We captured beetles in traps baited with D. brevicomis lure near the study site and stored beetles at -10degC until use. We inoculated selected trees by chorusing recently captured bark beetles into the phloem/xylem interface. Locations and densities of inoculations mimic the location and number of attacks on a paired tree in the attacked category within the same stress treatment and block. To inoculate trees, we removed a plug of bark ( $4 \mathrm{~mm}$ dia.) and inserted one beetle into the resulting cavity and crushed the beetle into the phloem/xylem interface by replacing the bark plug. We conducted all inoculations on the same day that attacks occurred on the attacked trees within the same block (e.g., twice weekly). We inoculated a total of 16 trees, with one tree in each of the trenched and untrenched treatments, across eight blocks from June 4 to August 5, 2014.

The control treatment had no manipulations. Furthermore, we took steps to prevent bark beetle attacks on trees in the non-attacked treatments (control, inoculated) by spraying the entire bole with $2.0 \%$ carbaryl on May 17, 2014 (DeGomez et al. 2006). The carbaryl spray was effective as we only observed a total of six attacks in 32 trees, and these were unsuccessful (lack of pitch tubes, boring dust, and frass). Every two weeks during the warm months (May to August) in 2014 and 2015, we determined tree status as dead or alive; a tree was categorized as dead when over $90 \%$ of its canopy turned brown or red.

Tree defense measurements

We took several types of measurements to characterize defenses of all 48 trees periodically as described in Kolb et al. (2019). We collected phloem from each tree at $1.5 \mathrm{~m}$ height to determine composition and concentrations of mono- and sesquiterpenes. We sampled phloem once a month from May to October 2014 and from May to September 2015. All trees were sampled on the same day by taking two phloem samples $(1.25 \mathrm{~cm}$ dia.) from opposite sides of the tree. Samples were kept in -20 degC until analysis. Detailed descriptions of extraction and chemical analysis were reported in Kolb et al. (2019).

Non-structural carbohydrate and diterpene resin analyses of xylem

We collected increment cores ( $5 \mathrm{~mm}$ dia.) from all trees throughout the experiment. Two cores were taken from opposite sides of each tree once a month from July to November, 2014 and from May to September, 2015 ( $n=20$ cores per tree). We used these cores to determine concentrations of NSCs and diterpene resin acids in the xylem over time. At each sampling date we selected the most current two consecutive rings from each of the two cores as the single year core did not provide enough tissue to conduct both NSC and diterpene analyses. For instance, in July 2014, we pooled the complete growth ring from 2013 and the partial (until July) ring from 2014. We freeze-dried these cores for six days (Labconco Corp., Kansas City, MO, USA) and ground them with a grinder (Tissue Lyzer II, QIAGEN, GER) for 20-30 seconds at a frequency of $30 \mathrm{sec}^{-1}$. Ground samples were then separated into two groups: One group was for NSC analysis (12-14 $\mathrm{mg}$ ) and the other was for diterpene analysis $(25-27 \mathrm{mg})$.

Non-structural carbohydrate analysis

We adapted methods from Mullin et al . (2021) for sugar and starch analyses. Briefly, ground samples were extracted with $1.6 \mathrm{~mL}$ ultra-pure water in a $2 \mathrm{~mL}$ glass tube. We placed tubes in a rack and enclosed the rack in steam above a tray of boiling water for $60 \mathrm{~min}$ and then closed the tube with its cap, and vortexed them for $30 \mathrm{sec}$. The resulting extract was separated into two $0.5 \mathrm{~mL}$ aliquots for soluble sugars and starch and stored at $+4 \operatorname{deg}$.

For soluble sugars (glucose, fructose, sucrose), tubes containing a $0.5 \mathrm{~mL}$ aliquot were centrifuged at 18,213 rcf for $15 \mathrm{~min}$ and the resulting supernatant was transferred into new $2 \mathrm{~mL}$ tubes containing $1.0 \mathrm{ml}$ of methanol and vortexed for $30 \mathrm{sec}$. Samples were incubated at room temperature for $90 \mathrm{~min}$ and centrifuged at $18,213 \mathrm{rcf}$ for $10 \mathrm{~min}$. Afterwards, $0.5 \mathrm{ml}$ of extracts were transferred to $2 \mathrm{ml}$ glass vials and stored at 
-40 degC. Sugars were analyzed using an Ultra High-Performance Liquid Chromatography (UHPLC, 1290 Infinity Agilent Tech., Santa Clara, CA, USA) fitted with an InfinityLab Poroshell 120 HILIC-Z column (2.1 x $100 \mathrm{~mm} 2.7 \mu \mathrm{m}$, Agilent Tech.) and an Evaporative Light Scattering Detector (ELSD, 1290 ELSD II, Agilent Tech.). A gradient analysis was performed using a binary solvent system of ultra-pure water with $0.02 \% \mathrm{v} / \mathrm{v}$ ammonium hydroxide (channel A) and acetonitrile (HPLC-grade) with $0.02 \% \mathrm{v} / \mathrm{v}$ ammonium hydroxide (channel B) flowing at $0.2 \mathrm{ml} \mathrm{min}^{-1}$. We calculated quadratic standard curves from three dilutions prepared from analytical standards to quantify glucose (Chemical Purity: 99\%), fructose (CP: 99\%), and sucrose (CP: 99.5\%). Soluble sugars were identified based on the retention time of the analytical standards. Concentrations of soluble sugars were reported as $\mu \mathrm{g} \mathrm{mg} \mathrm{m}^{-1}$ of dry weight.

Starch extraction was conducted using the second aliquot $(0.5 \mathrm{~mL})$ of sample extract. We used a series of enzymatic digestions to convert starch into gluconate-6-phosphate as adapted from Lahr \& Sala (2014) and Cale et al. (2019a). Extractions began with the steam bath procedure described above. Following the steam bath, samples were vortexed for $30 \mathrm{sec}$, then a $0.5 \mathrm{ml}$ aliquot that included suspended solids was transferred to a new $2 \mathrm{~mL}$ tube containing $0.5 \mathrm{~mL}$ of $\alpha$-amylase solution $\left(0.75 \mathrm{mg}\right.$ enzyme $\mathrm{mL}^{-1}$; Sigma-Aldrich) to convert starch to maltose and similar polysaccharides. The tubes were immediately vortexed for $30 \mathrm{sec}$, incubated in a water bath at $50^{\circ} \mathrm{C}$ for $16 \mathrm{hm}$ and then centrifuged $(18,213 \mathrm{rcf})$ for $20 \mathrm{~min}$. The resulting $0.5 \mathrm{~mL}$ of the supernatant was transferred into a new $2 \mathrm{~mL}$ tube containing with $0.5 \mathrm{~mL}$ of amyloglucosidase solution $2.5 \mathrm{~g}$ enzyme (Sigma-Aldrich) in $50 \mathrm{~mL}$ sodium acetate buffer (0.1 M, pH 4.5). The tubes were incubated in a $50{ }^{\circ} \mathrm{C}$ bath for $16 \mathrm{~h}$ to convert maltose and similar polysaccharides to glucose and fructose and then centrifuged $(18,213 \mathrm{rcf})$ for $15 \mathrm{~min}$. We transferred $0.02 \mathrm{~mL}$ of the final glucose extracts to $2 \mathrm{~mL}$ glass vials with starch derived glucose, which were immediately quantified by spectrophotometric analysis using the Synergy Microplate Reader H1 (BioTek, Winooski, VT, USA) at an absorbance of $340 \mathrm{~nm}$. Using methods reported in Mullin et al . (2021), we quantified the concentration of starch using two calibration curves. The first curve estimated glucose concentrations from the sample absorbance at $340 \mathrm{~nm}$, and the second estimated starch concentration from glucose concentration.

Diterpene resin acid extraction and analysis

Diterpenes were extracted from lyophilized ground tissue in $1 \mathrm{ml}$ of methanol, as adapted from Mullin et al . (2021). Samples were vortexed for $30 \mathrm{sec}$, then sonicated for $10 \mathrm{~min}$, and left for $24 \mathrm{~h}$ in the dark at room temperature, and then vortexed for $30 \mathrm{sec}$ and centrifuged $(18,213 \mathrm{rcf})$ for $15 \mathrm{~min}$. Extracts were transferred into $2 \mathrm{~mL}$ glass vials and stored at $-40 \mathrm{deg}$. Diterpenes were analyzed in an UHPLC, fitted with a reverse-phase InfinityLab Poroshell 120 EC-C18 column (2.1 x $150 \mathrm{~mm} 1.9 \mu \mathrm{m}$, Agilent Tech.) and a diode array detector (UV/Vis, $1290 \mathrm{DAD}$, Agilent Tech.). We performed a gradient analysis with a binary solvent system, a $1.7 \% \mathrm{v} / \mathrm{v}$ glacial acetic acid in distilled deionized water (channel A) and $100 \%$ pure methanol (channel B) flowing at $0.3 \mathrm{~mL} \mathrm{~min}{ }^{-1}$ for 17 min with solvent gradients. A $5 \mu$ linjection volume was used. The system began at $75 \% \mathrm{~B}$ for $1 \mathrm{~min}$, then increasing to $85 \% \mathrm{~B}$ over $9 \mathrm{~min}$, held for $2 \mathrm{~min}$, then decreased to $75 \% \mathrm{~B}$ over $14-17 \mathrm{~min}$, and held for $3 \mathrm{~min}$.

Diterpenes were quantified using analyte absorbance at wavelengths of 240,268 , and $282 \mathrm{~nm}$ (Kersten et al. 2006) and applying standard curves. The curves were generated from dilutions prepared from analytical standards of dehydroabietic acid (CP: >99\%), sandaracopiramic acid (CP: >90\%), levopiramic acid (CP: $>95 \%$ ), neoabietic acid (CP: >99\%), palustric acid (CP: >92\%), and abietic acid (CP: $>75 \%$ ). All chemicals were obtained from CanSynth Chem. Corporation (Toronto, ON, CAN), except for abietic acid from Sigma Aldrich. Diterpene concentrations were reported as $\mu \mathrm{g} \mathrm{mg}^{-1}$ of dried weight.

Data analysis

Since data showed large year-to-year variation, we analyzed each year separately (PerManova: $\mathrm{F}_{(1.313)}=4.45$, $\mathrm{P}=0.009)$. We first tested the dispersion of chemical profiles of all trees between sampling years $(2014,2015)$, and then between months within a year using NMDS ordination with Bray-Curtis distance (metaMDS function, packagevegan v2.5-6). We used PERMANOVA to verify whether chemical profiles changed over time with block set as strata (adonis2function, vegan package v2.5-6 in $\mathrm{R} v 4.0 .3$ ). An overview of our approach 
for each question is detailed below. Due to multiple permutations within our analyses, we summarized which treatments were compared to evaluate each research question in Table 1.

1. Do treatments influence NSCs of ponderosa pines? Since increment cores were collected from the same trees over multiple times, we used repeated measures analysis. We first checked the assumption of sphericity using Mauchly's test by testing whether starch, total sugars, and total NSCs change with month as a function of treatment (anova_test function, package rstatix v0.6.0). Results showed the data met sphericity assumptions and the correlation structure was avoided in final models. Therefore, linear mixed models were used to test the interaction between treatments and months with blocks and trees as nested random effects to identify whether treatments affected NSCs (function lmer, package lme4 v1.1-23). Residuals of NSC analyses were normally distributed and had homogeneous variances. We reported Type III tests using Satterthwaite's method and pairwise comparison p-values are Tukey adjusted (package emmeans v1.5.3).

Does trenching affect NSCs? We compared starch, total sugars and total NSCs between trenched-control $(\mathrm{n}=8)$ and untrenched-control $(\mathrm{n}=8)$ trees using the same analysis as above.

Do bark beetle attacks affect NSCs? We compared starch, total sugars and total NSCs between untrenchedattacked $(n=8)$ and untrenched-control $(n=8)$ trees using the same analysis as above.

Do microbial inoculations affect NSCs? We compared starch, total sugars and total NSCs between untrenched-inoculated $(\mathrm{n}=8)$ and untrenched-control $(\mathrm{n}=8)$ trees using the same analysis as above.

2. Is drought-biotic stressor interaction significant for NSCs and defense metabolites? In this and the research questions 3-5 below, we only focused on the phloem monoterpenes as there is currently no evidence that sesquiterpenes affect bark beetle biology.

We tested whether trenching impacted the effect of biotic stress (either bark beetle attacks or inoculation) on NSCs and terpenes. For each carbohydrate and defense compound, we ran separate models for bark beetle attack vs. control and inoculation vs. control treatments. Each repeated measures model included a full 3-way interaction with month, trenching and either beetle attack or inoculation treatment. Defense concentrations were log-transformed to meet assumptions of normality and homogeneity of variance but least squared means in original scale are presented.

3. Do changes in NSCs result in changes in defense metabolites? Using the same statistical approach as in the first question above, we tested whether the interaction of the NSCs, month and treatments affected concentrations of the total diterpenes or total monoterpenes with a repeated measures ANCOVA. Both monoterpenes and diterpenes were natural log-transformed to meet normality and homogeneity of variance assumptions. We removed the 3-way interaction from the final analysis because it was not significant and instead used a simpler model with fixed effects of NSCs, treatment, month, treatment by NSCs, and treatment by month with the same repeated measures model structure as above. Where there were significant interactions between treatment and NSCs, we tested whether slopes were different using Tukey's adjusted p-value (function lstrends in package lsmeans v2.27-2).

4. Do concentrations of NSCs and terpenes vary between dying and live trees? We used the same type of analyses as described under the first question above but only used the data from 2014 since six out of eight trees attacked by bark beetles died that year. We compared six dying trees with the two live trees in the trenched-attacked treatment for concentrations of starch, total sugars, total NSCs, total diterpenes, and total monoterpenes. We conducted overall pairwise comparisons between treatments with Tukey's adjusted p-values and then separately for each month with Sidak adjusted p-values (emmeansv1.5.3).

5. Can interactions between NSCs and terpenes explain tree mortality? We tested the correlation between average NSCs (starch, total sugars, or total NSCs) and terpenes (total diterpenes or monoterpenes) for the six dying trees in the trenched-attacked treatment in a Pearson correlation analysis. We also conducted the same correlation tests for live trees in the remaining six treatments including those that survived in the trenched-attacked treatment. We only used data from 2014 as all six dying trees in the trenched-attacked treatment died in 2014. 


\section{Results}

Overall, eight of the 48 total trees died during the two-year experiment. Bark beetle attacks occurred over 10 weeks, starting early June and ending in middle of August. Attacks peaked in late June and declined through August. All eight of the dead trees were attacked by bark beetles, with six of them being in the trenched-attacked treatment and two in the untrenched-attacked treatment. Trees in the combined treatment died sooner, with all of the mortality to trenched-attacked trees occurring in 2014 and all of the mortality to untrenched-attacked trees occurring in 2015.

As reported by Kolb et al . (2019), predawn water potential over the summer of 2013 averaged $-0.97 \mathrm{MPa}$ for trenched trees and $-0.83 \mathrm{MPa}$ for untrenched trees. In the second year of the experiment (2014), predawn water potential was approximately $0.5 \mathrm{MPa}$ more negative for trenched trees than untrenched trees between late May and early July during the typical spring drought period of the region (Fig. 1 in Kolbet al . 2019). Predawn water potential of trees in the trenched-attacked trees became much more negative than trees in all other treatments for the remainder of summer in 2014, reaching an average value of $-2.5 \mathrm{MPa}$ by middle of September compared with $-0.5 \mathrm{MPa}$ in other treatments. Differences in light saturated net photosynthetic rate among treatments in 2014 paralleled differences in predawn water potential, with values of trenched

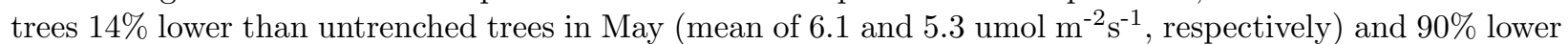
in late June (mean of 0.4 and $0.04 \mathrm{umolm}^{-2} \mathrm{~s}^{-1}$, respectively). Trenching continued to cause water stress during dry periods in the third year of the experiment (2015), with values of trenched trees $0.2 \mathrm{MPa}$ more negative than untrenched trees in late June.

In general, chemical profiles of ponderosa pine trees changed with treatment (Fig. 1, Fig. S1, Tables S1 \& $\mathrm{S} 2$ ), year (PerManova: $\left.\mathrm{F}_{(1.313)}=4.45, \mathrm{P}=0.009\right)$ and month (PerManova: $\left.\mathrm{F}_{(8.313)}=7.11, \mathrm{P}<0.001\right)$. Therefore, we tested whether the NCSs differed among treatments for each month and each year. The results showed that with the exception of September 2015, chemical profiles varied among treatments in the remaining sampling times (Fig. 1, Figs. S1 \& S2, Table S3). Note that terpenes of trees challenged with either bark beetle attacks or inoculated with crushed beetles represent "induced" concentrations, whereas terpenes of trees without any biological challenge treatments represent "constitutive" concentrations. Thus, the results should not be applied to define the question of whether terpene concentrations predict which trees live or die.

Do treatments influence NSCs of ponderosa pine trees? Overall, results show the importance of cumulative stresses in tree NSCs reduction in the xylem and mortality during drought as the effects of trenching on NSCs were negligible in trees without any additional biological treatment especially in the trenched-attacked treatment (Fig. 1, Table S2, Fig. S1). For instance, bark beetle attacks with trenching significantly lowered the total NSCs of trees relative to the trenching without such attacks (Fig. 1).

Effects of trenching on NSCs. Overall, chemical profiles did not differ between trenched-control and untrenched-control trees (Fig 2a, Table S4). We further tested if the NSCs were affected by trenching in each month. The difference was only significant in October 2014 (Fig. 3, Table S5) when starch, total sugars and total NSCs were higher in the trenched-control than the untrenched control.

Effects of bark beetle attacks on NSCs. For sugars, starch and total NSCs, treatments and month were significant, but treatment-month interaction was only significant for starch (Fig. 2b, Table S4). We then tested if NSCs were a function of beetle attacks in each month and found that bark beetle attacks significantly lowered sugars, starch, and total NSCs in July, August, September, October, November in 2014 and in May, June, August in 2015 (Fig. 3, Table S5).

Effects of crushed beetle inoculations on NSCs . Although treatment and month were significant for starch, total sugars, and total NSCs, the interaction was not (Fig. 2c, Table S4). We then tested whether NSCs were affected by inoculation in each month and found that inoculation significantly reduced total sugars and total NSCs in July, August, September, October in 2014 and in May, June, July, and August in 2015 and starch in July, August, and September in 2014 and in May, June, July, and August in 2015 (Fig. 3, Table S5). 
Trench-biotic stress interactions. We did not find significant interaction between trenching and biotic (beetle attacks or inoculations) treatments for NSCs and diterpenes ( $>>0.05)$. However, trenching did impact monoterpene concentrations in response to inoculation $\left(\mathrm{F}_{(1,21)}=4.69, \mathrm{P}=0.042\right)$. Trenched-inoculated trees had significantly greater monoterpene concentration $\left(8.85 \pm 1.89 \mu \mathrm{g} \mathrm{\textrm {mg } ^ { - 1 }}\right)$ than trenched-control $(2.80 \pm 0.60$ $\left.\mu \mathrm{g} \mathrm{mg}{ }^{-1}\right)$ or untrenched-control $\left(3.82 \pm 0.82 \mu \mathrm{g} \mathrm{mg}^{-1}\right)$ trees. Means of trenched-inoculated and untrenchedinoculated $\left(5.42 \pm 1.16 \mu \mathrm{g} \mathrm{mg}^{-1}\right)$ were statistically similar. Please note that monoterpenes

NSCs and defense metabolite interactions. Relationship between NSCs and diterpenes. There was a significant negative relationship between diterpenes and NSCs (Total NSCs: F $(1,267)=36.22, \mathrm{P}<0.001$, Fig. 4a; Total Sugars: $\mathrm{F}(1,270)=34.41, \mathrm{P}<0.001$, Fig. 4b; Starch: $\mathrm{F}(1,271)=25.49, \mathrm{P}<0.001$, Fig. 4c $)$. However, treatments did not affect these relationships (Fig. 4a).

Relationship between NSCs and monoterpenes. We did not find any relationship between monoterpenes and NSCs (Total NSCs: $\mathrm{F}(1,291)=0.082, \mathrm{P}=0.774$, Fig. 4d; Total Sugars: $\mathrm{F}(1,293)=0.080, \mathrm{P}=0.783$, Fig. 4e; Starch: $\mathrm{F}(1,265)=0.001, \mathrm{P}=0.969$, Fig. 4f). However, the relationship between starch and monoterpenes varied by treatments (Fig. 4f). Trees in the untrenched-attacked treatment had a significant negative relationship between monoterpenes and starch; in contrast, we found a significant positive relationship in the untrenched-inoculated and trenched-inoculated trees $(\mathrm{t}=-4.54, \mathrm{P}<0.001$, and $\mathrm{t}=-3.75, \mathrm{P}=0.003$, respectively). Moreover, although there was a marginal effect of treatment on the relationship between total NSCs and monoterpenes, we did not find a significant interaction for total sugars (significance of interactions are provided in Fig. 4 caption).

Concentrations of NSCs and terpenes between dying and live trees (2014 data only). Treatment, month, and their interaction significantly affected sugars, starch, or total NSCs (Suppl. Table S6). We then compared the dying and live trees in the same trenched-attacked category for each month and found that live trees had significantly higher total sugars, starch, and total NSCs than dying trees in August, September, October, and November in 2014 (Fig. 5).

We investigated similar relationships for diterpenes and monoterpenes of dying and live trees in the same treatment category. Treatment, time and their interaction were not significant effects for either terpenes (Table S6), showing that the amount of diterpenes or monoterpenes produced in the dying versus live trees were statistically similar (Fig. 5).

Comparisons of carbohydrates between the six dying trees in the trenched-attacked treatment and live trees in the untrenched-control treatment showed a significant effect of month (Table S7). In a pairwise comparison between treatments for each month, we found that live trees had significantly higher starch, total sugars, and total NSCs than dying trees starting from July until November in 2014 (Fig. 6). We only used the data in 2014 because all dying trees in the attacked-trenched category died in 2014.

We investigated relationships between the six dying trees in the trenched-attacked treatment and live trees in the untrenched-control treatment for diterpenes and monoterpenes. Although the two treatments did not vary significantly, the monthly comparisons showed that constitutive tissue of live trees had significantly lower diterpenes in August, September, October, and November than tissues of attacked trees (Fig. 6, Table S7). Likewise, for monoterpenes, the overall interaction was not significant but the monthly comparisons showed that live trees had significantly lower monoterpenes in July, August, September, and October than dying trees (Fig. 6).

Explanation of tree mortality by NSCs-terpene interactions. We investigated the relationship between NSCs and terpenes from 2014 for dying trees in the trenched-attacked treatment and all treatments of live trees averaged over months. We found significant negative relationships of NSCs with either with diterpenes or monoterpenes (Fig. 7). For live trees, diterpenes or monoterpenes had a significant negative relationship with starch, total sugars, or total NSCs. For dying trees, only monoterpenes had a significant relationship with starch $(\mathrm{P}<0.05)$. Other relationships between carbohydrates and terpenes were not significant. The low sample size for dying trees may have impacted the lack of significance in correlations compared to live trees. 


\section{Discussion}

This is the first experimental demonstration of seasonal changes in both carbohydrates and carbon-dependent defense metabolites through mortality of any conifer species during drought and bark beetle attacks in the field. Here, root trenching increased tree water stress which was manifested in reductions in both xylem water potential and leaf gas exchange, in agreement with previous studies with induced water stress (McCullough \& Wagner 1987; Woodruff \& Meinzer 2011; Hartmann 2015; Arango-Velez et al. 2016). We showed that trenching did not influence NSCs whereas both biotic challenge treatments reduced amounts of starch and sugars of trees. Furthermore, live trees had higher NSCs than dying trees, but the terpene concentrations did not vary between them. Only the trenched-beetle attacked trees depleted carbohydrates and died within the first year of bark beetle attacks.

We developed a new schematic representation of how mild drought alone or in combination with biotic stress has influenced NSCs (Fig. 8). Overall, our results show the importance of cumulative stress in tree carbohydrate depletion and mortality during drought, especially when considering that the effect of trenching alone on tree NSCs was negligible prior to bark beetle attacks or microbial inoculations (Fig. 8, Box 1). In fact, six of eight trees in the trench-attacked treatment died within 2-3 months of bark beetle attacks (2014) and at the time of death they had less than $10 \%$ of NSCs found in live trees. Since increased water stress following trenching had no impact on tree NSC amounts, our results suggest that trees stressed only by moderate drought may recover by compensating for carbohydrate loss (Gaylordet al. 2015; Galiano et al. 2017; Trugman et al . 2018; Gessler et al. 2020; He et al. 2020). However, if such trees are further stressed by biotic agents, the cumulative stressors (drought plus biotic agents) can lead to tree death (Fig. 8, Boxes 2 \& 3) (Anderegg et al. 2015; Camarero et al. 2015; Gaylord et al. 2015).

When bark beetles successfully enter the host, they consume phloem tissue to excavate oviposition and larval galleries, resulting in girdling and thus disrupting carbon transport in the phloem within the tree (Fig. 8, Box 3) (Paine et al. 1997; Wiley et al.2016). Bark beetles also carry propagules of a diverse community of fungal species (Frago et al . 2012); some of them have been shown to be at least moderately phytopathogenic (Krokene 2015). Once inside the tree, fungal propagules germinate and fungal hyphae spread and penetrate water conducting tissues in the xylem, blocking water conduction from the soil to the canopy and thus reducing photosynthesis, carbon assimilation, and NSC storage (Fig. 8, Box 2) (Lahr \& Krokene 2013; Arango-Velez et al. 2016; Wiley et al. 2016; Adamset al. 2017). Furthermore, hyphal growth and expansion inside the tree can be a significant carbon sink as fungal growth requires carbon (Fig. 8, Box 2) (Cale et al. 2019b). This may explain why both microbial inoculation and bark beetle attacks? without trenching?led to roughly similar depletion levels of NSCs in trees. However, inoculation of trenched trees did not result in any tree mortality as the bark beetle attacks on the trenched trees did, suggesting that the degree of stress imposed on trees appears to be proportional to the presence of both bark beetles and associated microbes. It is noteworthy for future assessments of tree defense capacity that using crushed beetles as the inoculum source generates higher variance to mean ratios of host chemistry than using standardized fungal inoculum (e.g., Keefover-Ringet al . 2016; Raffa et al . 2017). This result also suggests that single inoculation treatments, while useful for simulating beetle entry to access tree defensive capacity, cannot fully generate the effects of bark beetle mass attacks on declining tree health and mortality.

The current study suggested two mechanisms to support our main hypothesis, that continuous bark beetle attacks during tree water stress can deplete NSCs in tree stems relative to the trenching or bark beetle-alone treatments, and lead to tree mortality. Firstly, dying trees had much lower NSCs than live trees. In addition to our above explanation on the role of bark beetle-fungal activities in carbon biosynthesis and transport, bark beetle attacks created stronger sinks for carbohydrates than the trenching or inoculation alone treatments (Fig. 8, Box 3). Consequently, the amounts of terpenes produced in dying trees were similar to or higher than live trees (depending on the comparison and sampling date). Particularly, while NSC amounts were relatively stable in dying trees from July to November (2014), diterpene amounts increased over time particularly from July to September. In contrast, NSCs steadily increased in live trees but diterpenes sharply declined. In fact, at the time of death (October-November 2014), the dying trees had similar or higher concentrations 
of total diterpenes in the xylem and total monoterpenes in the phloem than live trees in the untrenchedcontrol treatment despite having only $5.8 \%$ of the total NSCs present in the live trees. These results are expected as conifer trees with low NSCs have been found to prioritize chemical defenses over growth and respiration (Huang et al . 2019). Our results suggest that terpene production in dying trees acted as a carbon sink because of the continuous allocation and remobilization of NSCs from storage to terpene biosynthesis (Goodsman et al. 2013; Roth et al . 2018; Huang et al. 2020). This likely reduced the NSC storage pool in the tree and altered carbon allocation to other tree functions (Sapes et al. 2021) (Fig. 8, Box 3), potentially resulting in carbon starvation in the tree stem (McDowell et al. 2008; McDowell \& Sevanto 2010).

Furthermore, lower NSC amounts within the trenched-attacked treatment for dying trees compared to live trees further supports a role of carbohydrates in tree survival (Fig. 8, Box 3). While six out of eight trees in the trenched-attacked treatment died, the remaining two trees were still alive at the end of the experiment. Although induced terpene amounts did not vary between dying and live trees in the trenched-attacked treatment, dying trees had considerably less sugars and starch than live trees. Thus, the differences between dying and live trees may be explained by the higher amounts of NSCs in the latter (Galiano et al. 2011; Poyatos et al. 2013; Dietze et al. 2014; Camarero et al. 2015). Similar to our results, Wileyet al. (2016) reported that phloem and xylem NSCs of lodgepole pine ( $P$. contorta var. latifolia) trees were affected by $D$. ponderosae attacks, with attacked trees having lower NSC amounts in both phloem and xylem than trees protected from such attacks (via experimental exclusion).

In conclusion, tree NSCs are critical for understanding the impacts of drought and bark beetles on conifers because of the importance of carbon-dependent terpenes as defenses against bark beetles. Using a multi-year field experiment, we showed that bark beetle colonization on drought-stressed trees reduced not only local carbohydrate availability for essential tree functions, but also inhibited tree's ability to replenish carbohydrate reserves. Furthermore, carbon-dependent terpenes and spreading fungal biomass in tree tissues become sinks for NSCs. Overall, this study enhances mechanistic understanding of how drought-mediated bark beetle attacks kill trees and underscores the importance of multiple stressors in altering tree carbohydrate source-sink relationships.

Acknowledgements - This field work was supported by McIntire-Stennis Program project accession no. 230732 from the USDA National Institute of Food and Agriculture. John Kaplan, Ansley Roberts, Teresa Reyes, and Patrick Dunn provided valuable help in the field; A Roberts and T Reyes were supported by the Hooper Undergraduate Research Program at Northern Arizona University and the National Science Foundation Research Experience for Undergraduates Program, respectively. The Northern Arizona University Centennial Forest provided the study site. NSERC to NE supported all the work at the University of Alberta. Non-structural carbohydrate and diterpene resin acid analyses were conducted in Erbilgin lab (https://sites.ualberta.ca/〜 erbilgin/).

Authors Contribution - SJB, MG, RH, and TK designed and implemented the field experiment and collected phloem and increment core samples; KK-R and KFR measured phloem monoterpenes; LZ, SZ, GI, S-HC prepared increment cores and conducted chemical analysis; SZ, JGK, and NE conducted statistical analyses; JGK, NE and S-HC prepared figures and tables; NE wrote the entire manuscript; all authors contributed to writing.

Data Availability - Upon acceptance of this manuscript, data will be posted at the University of Alberta Dataverse (https://dataverse.org/)

\section{References}

Adams HD, Zeppel MJB, Anderegg WRL, Hartmann H, Landshäusser SM, Tissue DT. 2017. A multi-species synthesis of physiological mechanisms in drought-induced tree mortality. Nature Ecology and Evolution1, $1285-1291$.

Allen CD, Macalady AK, Chenchouni H, Bachelet D, McDowell N, Vennetier M, Kitzberger et al., 2010. A global overview of drought and heat-induced tree mortality reveals emerging climate change risks for forests. 
Forest Ecology and Management 259, 660-684.

Anderegg WRL, Berry JA, Smith DD, Sperry JS, Anderegg LDL, Field CB. 2012. The roles of hydraulic and carbon stress in a widespread climate-induced forest die-off. Proceedings of the National Academy of Sciences USA 109, 233-237.

Anderegg WRL, Hicke JA, Fisher RS, Allen CD, Aukema J, Bentz B, Hood S, et al., 2015. Tree mortality from drought, insects, and their interactions in a changing climate. New Phytologist 208,674-683.

Arango-Velez A, El-Kayal W, Copeland CCJ, Zaharia LI, Lusebrink I, Cooke JEK. 2016. Differences in defense responses of Pinus contorta and Pinus banksiana to the mountain pine beetle fungal associateGrosmannia clavigera are affected by water deficit. Plant Cell Environment 39, 726-744.

Bentz BJ, Régnière J, Fettig CJ, Hansen EM, Hayes JL, Hicke JA, Kelsey RG, et al., 2010. Climate change and bark beetles of the Western United States and Canada: direct and indirect effects. BioScience60, 602613.

Boege K, Marquis RJ. 2005. Facing herbivory as you group up: the ontogeny of resistance in plants. Trends in Ecology 83 Evolution .20 , 441-448.

Breshears DD, Cobb NS, Rich PM, Price KP, Allen CD, Balice RG, Romme WH, et al., 2005. Regional vegetation die-off in response to global-change-type drought. Proceedings of the National Academy of Sciences USA 102, 15144-15148.

Cale AC, Klutsch GJ, Dykstra BC, Peters B, Erbilgin N. 2019a. Pathophysiological responses of pine defensive metabolites largely lack differences between pine species but vary with eliciting ophiostomatoid fungal species. Tree Physiology 39, 1121-1135.

Cale JA, Ding R, Wang F, Rajabzadeh R, Erbilgin N. 2019b. Ophiostomatoid fungi can emit the bark beetle pheromone verbenone and other semiochemicals in media amended with various pine chemicals and beetle-released compounds. Fungal Ecology 39, 285-295.

Camarero JJ, Gazol A, Sangüesa-Barreda G, Oliva J, Vicente-Serrano SM. 2015. To die or not to die: early warnings of tree dieback in response to a severe drought. Journal of Ecology 103, 44-57.

Celedon JM, Bohlmann J. 2019. Oleoresin defenses in conifers: chemical diversity, terpene synthases and limitations of oleoresin defense under climate change. New Phytologist 224, 1444-1463.

Chiu CC, Keeling CI, Bohlmann J. 2017. Toxicity of pine monoterpenes to mountain pine beetle. Scientific Reports 7, 8858 .

Choat B, Brodribgb TJ, Broderse CR, Duursma RA, López R, Medlyn BE. 2018. Triggers of tree mortality under drought. Nature 558, 531-539.

Creeden EP, Hicke JA, Buotte PC. 2014. Climate, weather, and recent mountain pine beetle outbreaks in the western United States.Forest Ecology and Management 312, 239-251.

DeGomez TE, Hayes CJ, Anhold JA,McMillin JD, ClancyKM, Bosu PP. 2006. Evaluation of insecticides for protecting southwestern ponderosa pines from attack by engraver beetles (Coleoptera: Curculionidae: Scolytinae).Journal of Economic Entomology 99, 393-400.

Deans RM, Brodribb TJ, Busch FA, Farquhar GD. 2020. Optimization can provide the fundamental link between leaf photosynthesis, gas exchange and water relations. Nature Plants 6, 1116-1125

Devine WD, Harrington TB. 2008. Belowground competition influences growth of natural regeneration in thinned Douglas-fir stands. Canadian Journal of Forest Research 38, 3085-3097.

DiGuistini S, Wang Y, Liao NY, Taylor G, Tanguay P, Feau N, et al. 2011. Genome and transcriptome analyses of the mountain pine beetle-fungal symbiont Grosmannia clavigera, a lodgepole pine pathogen. Proceedings of National Academy of Sciences, USA. 108, 2504-2509. 
Dietze MC, Sala A, Carbone MS, Czimczik CI, Mantooth JA, Richardson AD, Vargas R. 2014. Nonstructural carbon in woody plans. Annual Review of Plant Biology 65, 667-87.

Erbilgin N. 2019. Phytochemicals as mediators for host range expansion of a native invasive forest insect herbivore. New Phytologist221, 1268-1278.

Erbilgin N, LJ Colgan. 2012. Differential effects of plant ontogeny and damage type on phloem and foliage monoterpenes in jack pine (Pinus banksiana). Tree Physiology 32, 946-957

Erbilgin N, Cale JA, Lusebrink I, Najar A, Klutsch JG, Sherwood P, Bonello PE, Evenden ML. 2017. Waterdeficit and fungal infection can differentially affect the production of different classes of defense compounds in two host pines of mountain pine beetle. Tree Physiology 37, 338-350.

Frago E, Dicke M, Godfray HCJ. 2012. Insect symbionts as hidden players in insect-plant interactions. Trends in Ecology and Evolution 27, 705-711.

Galiano L, Martínez-Vilalta J, Lloret F. 2011. Carbon reserves and canopy defoliation determine the recovery of Scots pine 4 yr after a drought episode. New Phytologist 190, 750-759.

Galiano L, Timofeeva G Saurer M, Siegwolf R, Martínez-Vilalta J, Hommel R, Gessler A. 2017. The fate of recently fixed carbon after drought release: towards unravelling $\mathrm{C}$ storage regulation in Tilia platyphyllos and Pinus sylvestris . Plant Cell Environment40, 1711-1724.

Gaylord ML, Kolb TE, Wallin KF, Wagner MR. 2006. Seasonality and lure preference of bark beetles (Curculionidae: Scolytinae) and associates in a northern Arizona ponderosa pine forest. Environmental Entomology 35, $37-47$.

Gaylord ML, Kolb TE, Pockman WT, Plaut JA, Yepez EA, Macalady AK, Pangle RE, McDowell NG. 2013. Drought predisposes piñon-juniper woodlands to insect attacks and mortality. New Phytologist 198 , $567-578$.

Gaylord ML, Kolb TE, McDowell NG. 2015. Mechanisms of piñon pine mortality after severe drought: a retrospective study of mature trees. Tree Physiology 35, 806-816.

Gely C, Laurance SGW, Stork NE. 2020. How do herbivorous insects respond to drought stress in trees? Biological Review 95 , 434-448.

Gessler A, Bottero A, Marshal J, Arend M. 2020. The way back: recovery of trees from drought and its implication for acclimation. New Phytologist 228 , 1704-1709.

Goodsman DW, Lusebrink I, Landh \euroausser SM, Erbilgin N, Lieffers VJ. 2013. Variation in carbon availability, defense chemistry and susceptibility to fungal invasion along the stems of mature trees. New Phytologist 197, 586-594.

Hartmann H. 2015. Carbon starvation during drought-induced tree mortality - are we chasing a myth? Journal of Plant Hydraulogy2, e-005. https://doi.org/10.20870/jph.2015. e005.

Hartmann H, Trumbore S. 2016. Understanding the roles of nonstructural carbohydrates in forest trees from what we can measure to what we want to know. New Phytologist 211 , 386-403

Hartmann H, Moura CF, Anderegg WR, Ruehr N, Salmon Y, Allen CD, Arndt SK, et al., 2018. Research frontiers for improving our understanding of drought-induced tree and forest mortality. New Phytologist 218 , $15-28$.

He W, Liu H, Qi Y, Liu F, Zhu X. 2020. Patterns in nonstructural carbohydrate contents at the tree organ level in response to drought duration. Global Change Biol ogy 26 , 3627-3638.

Hofstetter RW, Dinkins-Bookwalter J, Davis TS, Klepzig KD. 2015. Symbiotic associations of bark beetles. In: Vega FE, Hofstetter RH (eds) Bark beetles: biology and ecology of native and invasive species. Academic Press, Elsevier Inc, San Diego, CA, pp 209-245. 
Huang J, Hammerbacher A, Weinhold A, Reichelt M, Gleixner G, Behrendt T, van Dam NM, Sala, A, Gershenzon J, Trumbore S, Hartmann H. 2019. Eyes on the future - evidence for trade-offs between growth, storage and defense in Norway spruce. New Phytologist 222 : 144-158.

Huang J, Kautz M, Trowbridge AM, Hammerbacher A, Raffa KF, Adams HD, Goodsman DW, et al., 2020. Tree defence and bark beetles in a drying world: Carbon partitioning, functioning and modelling. New Phytologist 225 , 26-36.

Hussain A, Classens G, Guevara-Rozo S, Cale JA, Rajabzadeh R, Peters BR, Erbilgin N. 2020. Spatial variation in soil available water holding capacity alters carbon mobilization and allocation to chemical defenses along jack pine stems. Environmental and Experimental Botany171 , 103902.

Keefover-Ring K, Trowbridge A, Mason CJ, Raffa KF. 2016. Rapid induction of multiple terpenoid groups by ponderosa pine in response to bark beetle-associated fungi. Journal of Chemical Ecology 42: 1-12

Keeling CI, Bohlmann J. 2006. Genes, enzymes and chemicals of terpenoid diversity in the constitutive and induced defence of conifers against insects and pathogens. New Phytologist 170 , 657-675.

Kersten PJ, Kopper BJ, Raffa KF, Illman BL. 2006. Rapid analysis of abietanes in conifers. Journal of Chemical Ecology 22, 1367-1388.

Kolb TE, Fettig CJ, Ayres MP, Bentz J, Hicke JA, Mathiasen R, Stewart JE, Weed AS. 2016. Observed and anticipated impacts of drought on forest insects and diseases in the United States. Forest Ecology and Management $\mathbf{3 8 0}, 321-334$.

Kolb TE, Keefover-Ring K, Burr SJ, Hofstetter R, Gaylord M, Raffa KF. 2019. Drought-mediated changes in tree physiological processes weaken tree defenses to bark beetle attack. Journal of Chemical Ecology45, 888-900.

Kopper BJ, Illman BL, Kersten PJ, Klepzig KD, Raffa KF. 2005. Effects of diterpene acids on components of a conifer bark beetle-fungal interaction: tolerance by Ips pini and sensitivity by its associate Ophiostoma ips . Environmental Entomology34, 486-493.

Krokene P. 2015. Conifer defense and resistance to bark beetles," in Bark Beetles: Biology and Ecology of Native and Invasive Species. eds. F. E. Vega and R. W. Hofstetter (Amsterdam, The Netherlands: Elsevier Academic Press), 177-207.

Lahr EC, Krokene P. 2013. Conifer stored resources and resistance to a fungus associated with the spruce bark beetle Ips typographus.PLoS ONE 8 , e72405.

Lahr EC, Sala A. 2014. Species, elevation, and diameter affect whitebark pine and lodgepole pine stored resources in the sapwood and phloem: implications for bark beetle outbreaks. Canadian Journal of Forest Research 44, 1312-1319.

Li W, HartmannH, AdamsHD, Zhang H, Jin C, Zhao C, Guan D, Wang A, Yuan F, Wu J. 2018. The sweet side of global change-dynamic responses of non-structural carbohydrates to drought, elevated $\mathrm{CO}_{2}$ and nitrogen fertilization in tree species. Tree Physiology38, 1706-1723.

Lombardero M, Ayres MP, Lorio PL, Ruel J. 2000. Environmental effects on constitutive and inducible resin defences of Pinus taeda.Ecology Letters 3 , 329-339.

Lusebrink I, Evenden ML, Guillaume Blanchet F, Cooke JEK, Erbilgin N. 2011. Effect of water stress and fungal inoculation on monoterpene emission from an historical and a new pine host of the mountain pine beetle. Journal of Chemical Ecology $37,1013-1026$.

McCullough DG, Wagner MR. 1987. Evaluation of four techniques to assess vigor of water-stressed ponderosa pine. Canadian Journal of Forest Research 17 , 138-145. 
McDowell NG, Sevanto S. 2010. The mechanisms of carbon starvation: how, when, or does it even occur at all? New Phytologist 186 , 264-266.

McDowell NG, Pockman WT, Allen CD, Breshears DD, Cobb N, Kolb T, Plaut J, et al., 2008. Mechanisms of plant survival and mortality during drought: why do some plants survive while others succumb to drought? New Phytologist $178,719-739$.

McDowell NG, Beerling DJ, Breshears DD, Fisher RA, Raffa KF, Stitt M. 2011. The interdependence of mechanisms underlying climate-driven vegetation mortality. Trends in Ecology and Evolution 26 , 523-532.

Meddens AJH, Hicke JA, Macalady AK, Buotte PC, Cowles TR, Allen CD. 2014. Patterns and causes of observed piñon pine mortality in the southwestern United States. New Phytologist 206 , 91-97.

Meir P, Mencuccini M, Dewar RC. 2015. Drought-related tree mortality: addressing the gaps in understanding and prediction. New Phytologist 207 , 28-33.

Mitchell PJ, O'Grady AP, Tissue DT, White DA, Ottenschlaeger ML, Pinkard EA. 2013. Drought response strategies define the relative contributions of hydraulic dysfunction and carbohydrate depletion during tree mortality. New Phytologist 197, 862-872.

Moreira Z, Glauser G, Abdala-Robert L. 2017. Interactive effects of plant neighbourhood and ontogeny on insect herbivory and plant defensive traits. Scientific Reports 7, 4047.

Mullin M, Klutsch JG, Cale JA, Hussain A, Zhao S, Whitehouse C, Erbilgin N. 2021. Primary and secondary metabolite profiles of lodgepole pine trees change with elevation, but not with latitude. Journal of Chemical Ecology 47, 280-293

Negrón JF, McMillin JD, Anhold JA, Coulson D. 2009. Bark beetle-caused mortality in a drought-affected ponderosa pine landscape in Arizona, USA. Forest Ecology and Management 257, 1353-1362.

Netherer S, Panassiti B, Pennerstorfer J, Matthews B. 2019. Acute drought is an important driver of bark beetle infestation in Austrian Norway spruce stands. Frontiers Forest Global Change 2,39 doi: 10.3389/ffgc.2019.00039.

Öhrn P, Berlin M, Elfstand M, Krokene P, Jönsson AM. 2021. Seasonal variation in Norway spruce response to inoculation with bark beetle-associated bluestain fungi one year after a severe drought.Forest Ecology and Management 496 : 119443

Paine TD, Raffa KF, Harrington TC. 1997. Interactions among scolytid bark beetles, their associated fungi, and live host conifers. Annual Review of Entomology 42, 179-206.

Pile LS, Meyer MD, Rojas R, Roe O, Smith MT. 2019. Drought impacts and compounding mortality on forest trees in the Southern Sierra Nevada. Forests 10, 237 doi:10.3390/f10030237.

Poyatos R, Aguadé D, Galiano L, Mencuccini M, Martínez-Vilalta J. 2013. Drought-induced defoliation and long periods of near-zero gas exchange play a key role in accentuating metabolic decline of Scots pine.New Phytologist 200, 388-401.

Raffa KF, Powell EN, Townsend PA. 2013. Temperature-driven range expansion of an irruptive insect heightened by weakly coevolved plant defenses. Proceedings of the National Academy of SciencesUSA 110, 21932198 .

Raffa KF, Mason CJ, Bonello P, Cook S, Erbilgin N, Keefover-Ring K, et al., 2017. Defense syndrome in lodgepole-whitebark pine ecosystems related to degree of historical exposure to mountain pine beetle.Plant Cell Environment 40: 1791-1806

Roth M, Hussain A, Cale JA, Erbilgin N. 2018. Successful colonization of lodgepole pine trees by mountain pine beetle increased monoterpene production and exhausted carbohydrate reserves. Journal of Chemical Ecology 44, 209-214. 
Sala A, Woodruff D, Meinzer F. 2012. Carbon dynamics in trees: feast or famine? Tree Physiology 32, 764-775

Sapes G, Demaree P, Lekberg Y, Sala A. 2021. Plant carbohydrate deplete impairs water relations and spread via ectomycorrhizal networks. New Phytologist 229, 3172-3183

Savage M. 1994. Anthropogenic and natural disturbance and patterns of mortality in a mixed conifer forest in California. Canadian Journal of Forest Research 24, 1149-1159.

Simler-Williamson AB, Rizzo DM, Cobb RC. 2019. Interacting effects of global change on forest pest and pathogen dynamics. Annual Review of Ecology, Evolution and Systematics. 50, 381-403.

Stephenson NL, Das AJ, Ampersee NJ, Bulaon BM, Yee JL. 2019. Which trees die during drought? The key role of insect host-tree selection. Journal of Ecology 107, 2383-2401.

Trugman AT, Detto M, Bartlett MK, Medvigy D, Anderegg WRL, Schwalm C, Schaffer B, Pacala SW. 2018. Tree carbon allocation explains forest drought-kill and recovery patterns. Ecology Letters 21 :1552-1560.

Turtola S, Manninen AM, Rikala R, Kainulainen P. 2003. Drought stress alters the concentration of wood terpenoids in scots pine and Norway spruce seedlings. Journal of Chemical Ecology 29,1981-1995.

Ullah A, Klustch JG, Erbilgin N. 2021. Production of complimentary defense metabolites reflects a coevolutionary arms race between a host plant and the mutualistic bark beetle-fungal complex. Plant Cell Environment - In-Press. doi.org/10.1111/pce.14100

USDA Forest Service. 2002. Forest Insect and Disease Conditions on the United States 2004. R3-02-01. USDA-Forest Service, Forest Service, Forest Health Protection, August 2005. 142 pp. http://www.fs.fed.us/r3/publications/documents/fidc2002.pdf, last accessed 18 July, 2008.

Young DJN, Stevens JT, Earles JM, Moore J, Ellis A, Jirka AL, Latimer AM. 2017. Long-term climate and competition explain forest mortality patterns under extreme drought. Ecology Letters 20, 78-86.

Wiley E, Rogers BJ, Hodgkinson R, Landhäusser SM. 2016. Nonstructural carbohydrate dynamics of lodgepole pine dying from mountain pine beetle attack. New Phytologist 209, 550-562.

Woodruff DR, Meinzer FC. 2011. Water stress, shoot growth and storage of non-structural carbohydrates along a tree height gradient in a tall conifer. Plant Cell Environment 34, 1920-30.

Table 1. Treatments included in the five research questions listed in the Methods and Materials. Treatments (C: Control, I: Inoculated, A: Attacked). Only cells with "X" in a row were included in the analysis. For question 4, only the trenched-attacked treatment was included. For question 5, dying trees in the trenchedattacked treatment were compared with live trees in all six treatments including those that survived in the trenched-attacked treatment.

Research

questions

investigated

Trenched

1. Do treatments

influence

NSCs of

ponderosa

pines?

Does trenching

affect

carbohydrates?
1. Do

treatments

influence

NSCs of

ponderosa

pines?

$\mathrm{X}$
Trenched

A

1. Do

treatments

influence

NSCs of

ponderosa

pines?
1. Do

treatments

influence

NSCs of

ponderosa

pines?
C

1. Do

treatments

influence

NSCs of

ponderosa

pines?

$\mathrm{X}$
Untrenched A

1. Do treatments influence NSCs of ponderosa pines? 


\begin{tabular}{|c|c|c|c|c|c|c|}
\hline $\begin{array}{l}\text { Research } \\
\text { questions } \\
\text { investigated }\end{array}$ & Trenched & Trenched & Trenched & Untrenched & Untrenched & Untrenched \\
\hline $\begin{array}{l}\text { Do bark beetle } \\
\text { attacks affect } \\
\text { carbohydrates? }\end{array}$ & & & & $\mathrm{X}$ & & $\mathrm{X}$ \\
\hline $\begin{array}{l}\text { Does microbial } \\
\text { inoculations } \\
\text { affect } \\
\text { carbohydrates? }\end{array}$ & & & & $\mathrm{X}$ & $\mathrm{X}$ & \\
\hline $\begin{array}{l}\text { 2. Is } \\
\text { drought- } \\
\text { biotic } \\
\text { stressor } \\
\text { interaction } \\
\text { significant } \\
\text { for NSCs } \\
\text { and terpene } \\
\text { concentrations- } \\
\text { bark beetle } \\
\text { attacks }\end{array}$ & $\mathrm{X}$ & & $\mathrm{X}$ & $\mathrm{X}$ & & $\mathrm{X}$ \\
\hline $\begin{array}{l}\text { Is } \\
\text { drought-biotic } \\
\text { stressor } \\
\text { interaction } \\
\text { significant for } \\
\text { NSCs and } \\
\text { terpene } \\
\text { concentrations- } \\
\text { inoculations }\end{array}$ & $\mathrm{X}$ & $\mathrm{X}$ & & $\mathrm{X}$ & $\mathrm{X}$ & \\
\hline $\begin{array}{l}\text { 3. Do } \\
\text { changes in } \\
\text { NSCs result } \\
\text { in changes } \\
\text { in defense } \\
\text { metabolites? }\end{array}$ & $\mathrm{X}$ & $\mathrm{X}$ & $\mathrm{X}$ & $\mathrm{X}$ & $\mathrm{X}$ & $\mathrm{X}$ \\
\hline $\begin{array}{l}\text { 4. Do con- } \\
\text { centrations } \\
\text { of carbohy- } \\
\text { drates and } \\
\text { terpenes } \\
\text { vary between } \\
\text { dying and } \\
\text { live trees } \\
\text { within the } \\
\text { same } \\
\text { treatment? }\end{array}$ & & & $\mathrm{X}$ & & & \\
\hline
\end{tabular}




\begin{tabular}{|c|c|c|c|c|c|c|}
\hline $\begin{array}{l}\text { Research } \\
\text { questions } \\
\text { investigated }\end{array}$ & Trenched & Trenched & Trenched & Untrenched & Untrenched & Untrenched \\
\hline $\begin{array}{l}\text { Do } \\
\text { concentrations } \\
\text { of } \\
\text { carbohydrates } \\
\text { and terpenes } \\
\text { vary between } \\
\text { dying and } \\
\text { control live } \\
\text { trees? }\end{array}$ & & & $\mathrm{X}$ & $\mathrm{X}$ & & \\
\hline $\begin{array}{l}\text { 5. Can } \\
\text { interactions } \\
\text { between car- } \\
\text { bohydrates } \\
\text { and terpenes } \\
\text { explain tree } \\
\text { mortality? }\end{array}$ & $\mathrm{X}$ & $\mathrm{X}$ & $\mathrm{X}$ & $\mathrm{X}$ & $\mathrm{X}$ & $\mathrm{X}$ \\
\hline
\end{tabular}

\section{Figure Captions}

Figure 1. Mean $( \pm \mathrm{SE})\left(\mu \mathrm{g} \mathrm{mg}^{-1}\right.$ of dried weight) monthly variation of starch, total sugars, total nonstructural carbohydrates (NSC), and diterpenes of Pinus ponderosa trees in six treatments from July to November 2014 and May to September 2015.

Figure 2. Means $( \pm \mathrm{SE})\left(\mu \mathrm{g} \mathrm{mg}{ }^{-1}\right.$ of dried weight) of starch, total sugars, and total non-structural carbohydrates (NSCs) of Pinus ponderosa trees in six treatments. Trees included in each comparison were reported in Table 1.

Figure 3. Monthly means $( \pm \mathrm{SE})\left(\mu \mathrm{g} \mathrm{mg}^{-1}\right.$ of dried weight) of starch, total sugars, and total non-structural carbohydrates (NSCs) of Pinus ponderosa trees in different comparisons. * denotes that concentrations vary in a given month (95\% confidence level adjusted with Sidak method for two estimates). Suppl. Table S4 shows statistical results.

Figure 4. Relationship between concentrations of total diterpenes and non-structural carbohydrates (NSCs) of Pinus ponderosa trees by treatments. Regression lines for: (a) NSC, (b) total sugars, and (c) starch are from repeated measures ANCOVAs on the log of total diterpenes. Top figures: Significance of interaction between NSCs and total diterpenes were as follows: (a) Total NSCs: $\mathrm{F}_{(5,256)}=1.96, \mathrm{P}=0.085$, (b) Total sugars: $\mathrm{F}_{(5,258)}=2.18, \mathrm{P}=0.057$, and (c) Starch: $\mathrm{F}_{(5,254)}=1.34, \mathrm{P}=0.247$. Bottom figures. Significance of interaction between NSCs and total monoterpenes were as follows: $(d)$ Total NSCs: $F_{(5,255)}=2.07, P=0.069$, (e) Total sugars: $\mathrm{F}_{(5,254)}=1.58, \mathrm{P}=0.166$, (f) Starch: $\mathrm{F}_{(5,286)}=4.98, \mathrm{P}=0.0002$. Degrees of freedom were calculated with Satterthwaite's method.

Figure 5. Monthly means $( \pm \mathrm{SE})\left(\mu \mathrm{g} \mathrm{mg}{ }^{-1}\right.$ of dried weight $)$ of carbohydrates, total diterpenes, and total monoterpenes of dying and live Pinus ponderosa trees in the trenched-attacked treatment. Data are from 2014. * shows months where differences among treatments are significant (95\% confidence level adjusted with Sidak method for two estimates).

Figure 6. Monthly means $( \pm \mathrm{SE})\left(\mu \mathrm{g} \mathrm{mg}^{-1}\right.$ of dried weight) of carbohydrates, total diterpenes, and total monoterpenes of dying Pinus ponderosa trees in the trenched-attacked treatment and live trees in the untrenched-control treatment. Data are from 2014. ${ }^{*}$ shows months where differences among treatments are significant (95\% confidence level adjusted with Sidak method for two estimates). 
Figure 7. Relationship between carbohydrate and terpene concentrations from 2014 for dying Pinus ponderosa trees in the trenched-attacked category and all treatment categories of live trees averaged over months. Solid (dying trees) and dashed (live trees) trend lines indicate significant Pearson correlations. Dying trees $\mathrm{n}=8$ and live trees $\mathrm{n}=42$ (except diterpene comparisons $\mathrm{n}=40$ ). Total non-structural carbohydrates (NSC) are the sums of starch and total sugar concentrations.

Figure 8. Schematic representation of how mild drought alone or in combination with pathogenic microbial infection and bark beetle attacks affect carbohydrates and carbon-dependent defense metabolites (terpenes) in pines.

\section{Hosted file}

Figures.pdf available at https://authorea.com/users/424116/articles/529271-combined-droughtand-bark-beetle-attacks-deplete-non-structural-carbohydrates-and-promote-death-ofmature-pine-trees 